\title{
Stress cardiomyopathy (Takotsubo) following radioactive iodine therapy
}

\author{
Anastasia Dimakopoulou, Karunakaran Vithian', David Gannon ${ }^{1}$ and Allan Harkness ${ }^{1}$ \\ Whittington Hospital, London, UK \\ ${ }^{1}$ Colchester Hospital University NHS Foundation Trust, Colchester, UK
}

Correspondence should be addressed to A Dimakopoulou Email

anastasia.dimakopoulou@ nhs.net

\section{Summary}

A 55-year-old female patient presented to the endocrine clinic with Grave's disease. She was initially treated with carbimazole. After an early relapse, a decision was made to proceed with radioactive iodine therapy. Four days after radioiodine administration, she presented to the emergency department with chest tightness and dyspnea due to heart failure. Biochemistry revealed thyrotoxicosis and significantly elevated Troponin-T. There was ST segment elevation on electrocardiography. However, coronary angiography was normal. Ventricular function was fully restored after 6 weeks of supportive medical management. A diagnosis of stress cardiomyopathy following radioactive iodine therapy was made. This is the second case reported in the literature so far to the best of our knowledge.

\section{Learning points:}

- Stress cardiomyopathy in the context of radiation thyroiditis is a rare complication following radioiodine therapy.

- A degree of awareness is essential because the approach is multidisciplinary. Management is mainly supportive and cardiac dysfunction is completely reversible in most cases.

- The pathogenesis of this condition remains unclear. Post-menopausal women and susceptible individuals appear to be pre-disposed.

\section{Background}

Stress cardiomyopathy after radioactive iodine therapy was originally reported in 2009 (1). We would like to report this case in order to increase awareness among endocrinologists, cardiologists and general medical physicians. Stress cardiomyopathy is a condition characterised by reversible left ventricular dysfunction. The precipitant is usually a highly stressful experience with significant sympathetic drive. Thyrotoxicosis in the context of radiation thyroiditis represents a state of increased adrenergic activity and can potentially lead to stress cardiomyopathy in pre-disposed individuals.

\section{Case presentation}

A 55-year-old female patient was assessed in the endocrine clinic with facial sweating and dry lips. She did not have palpitations, heat intolerance or other symptoms suggestive of hyperthyroidism. She had a multinodular goitre, which was confirmed on thyroid ultrasound. There were no signs of thyroid ophthalmopathy. Her initial presentation was consistent with subclinical hyperthyroidism. Nine months later, biochemical hyperthyroidism developed with a thyroid-stimulating hormone (TSH) of $<0.01 \mathrm{mU} / \mathrm{l}$, a free thyroxine $\left(\mathrm{T}_{4}\right)$ of $42.2 \mathrm{pmol} / \mathrm{l}$ and free triiodothyronine $\left(\mathrm{T}_{3}\right)$ of $18 \mathrm{pmol} / \mathrm{l}$. Carbimazole was 


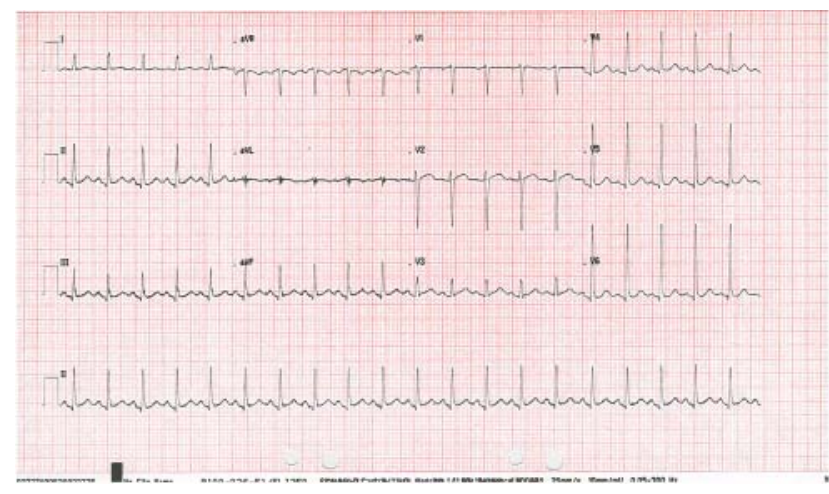

Figure 1

ECG showing borderline ST elevation in II/III leads.

started and free $\mathrm{T}_{4}$ normalised. In an attempt to reduce the dose of carbimazole, her Grave's disease relapsed. After 12 months of antithyroid treatment, TSH became undetectable and free $\mathrm{T}_{4}$ increased to $32.8 \mathrm{pmol} / \mathrm{l}$. Our patient was keen to proceed with radioactive iodine therapy. One month prior radioiodine, free $\mathrm{T}_{4}$ was within normal range at $19.6 \mathrm{pmol} / \mathrm{l}$ and the dose of carbimazole was $20 \mathrm{mg}$ daily. Four days after radioactive iodine (400 MBq) administration, she presented to the emergency department with chest tightness and dyspnea.

On arrival to the emergency department, clinical examination revealed signs of heart failure. There were bilateral crackles on chest auscultation and electrocardiography was consistent with an acute coronary event. Biochemistry confirmed raised cardiac markers. Therefore, urgent transfer to the local cardiothoracic centre was scheduled for possible primary coronary intervention.

\section{Investigation}

Original electrocardiography showed sinus tachycardia at 121 per min and borderline ST elevation in II/III leads (Fig. 1). Troponin-T was elevated at $438 \mathrm{ng} / \mathrm{l}$ (normal range $<15 \mathrm{ng} / \mathrm{l})$.

Thyroid function testing was consistent with undetectable TSH and free $\mathrm{T}_{4}$ of $77.7 \mathrm{pmol} / \mathrm{l}$ (Table 1).
Coronary angiography performed at the cardiothoracic centre was normal. Echocardiography showed focal apical akinesia of left ventricular (LV) segments, apical ballooning and regional wall motion abnormalities. Systolic function was impaired with an ejection fraction of $30-35 \%$ (Fig. 2).

\section{Outcome and follow-up}

Our patient was treated with propylthiouracil, ramipril and carvedilol. She also completed a course of oral prednisolone for radiation thyroiditis, a painful inflammation of the thyroid gland that occurs after radioiodine therapy (2).

Six weeks after the episode of radiation thyroiditis, echocardiography showed normal left ventricular function with ejection fraction of 55\% (Fig. 3). Ramipril was stopped. Mayo's revised criteria were used to confirm the diagnosis of Takotsubo cardiomyopathy (3) (4): i) transient hypokinesis or dyskinesis of left ventricular mid segments with apical ballooning; ii) absence of obstructive coronary disease; iii) new ST segment elevation or T wave inversion on electrocardiography; and iv) absence of pheochromocytoma and myocarditis.

Three months after radioiodine, TSH increased to $2.18 \mathrm{mU} / 1$ with free $\mathrm{T}_{4}$ of $6.2 \mathrm{pmol} / \mathrm{l}$. $\mathrm{L}^{-} \mathrm{T}_{4}$ was successfully introduced. No further cardiology input is required.

\section{Discussion}

Stress cardiomyopathy is a rare complication of thyrotoxicosis, which may occur in the context of radiation thyroiditis. The latter affects $1 \%$ of patients receiving radioiodine therapy and lasts for a few weeks. Radiation thyroiditis is associated with transient destructionmediated release of thyroid hormones and this can have a significant impact on cardiovascular physiology. The effects of $\mathrm{T}_{3}$, the active cellular form of thyroid hormone, lead to increased cardiac output in patients with hyperthyroidism resembling a state of increased adrenergic activity (5).

Table 1 Thyroid function testing

\begin{tabular}{|c|c|c|c|c|c|c|c|}
\hline & Presentation & $\begin{array}{c}\text { Initiation of } \\
\text { antithyroid } \\
\text { medication }\end{array}$ & $\begin{array}{l}\text { Euthyroid } \\
\text { in } 9 \text { months }\end{array}$ & $\begin{array}{c}\text { Relapse } \\
\text { in } 12 \text { months }\end{array}$ & $\begin{array}{l}\text { Euthyroid } \\
1 \text { month } \\
\text { before } \text { I }^{131}\end{array}$ & $\begin{array}{l}\text { Thyrotoxicosis } \\
4 \text { days after } I^{131}\end{array}$ & $\begin{array}{l}\text { Hypothyroid } \\
3 \text { months } \\
\text { after after I }\end{array}$ \\
\hline $\mathrm{TSH}(\mathrm{mU} / \mathrm{l})$ & $<0.01$ & $<0.01$ & $<0.01$ & $<0.01$ & $<0.03$ & $<0.01$ & 2.18 \\
\hline $\mathrm{FT}_{4}(\mathrm{pmol} / \mathrm{l})$ & 18.6 & 42.2 & 18.2 & 32.8 & 19.6 & 77.7 & 6.2 \\
\hline FT3 (pmol/l) & & 18 & & & & 21.1 & \\
\hline
\end{tabular}




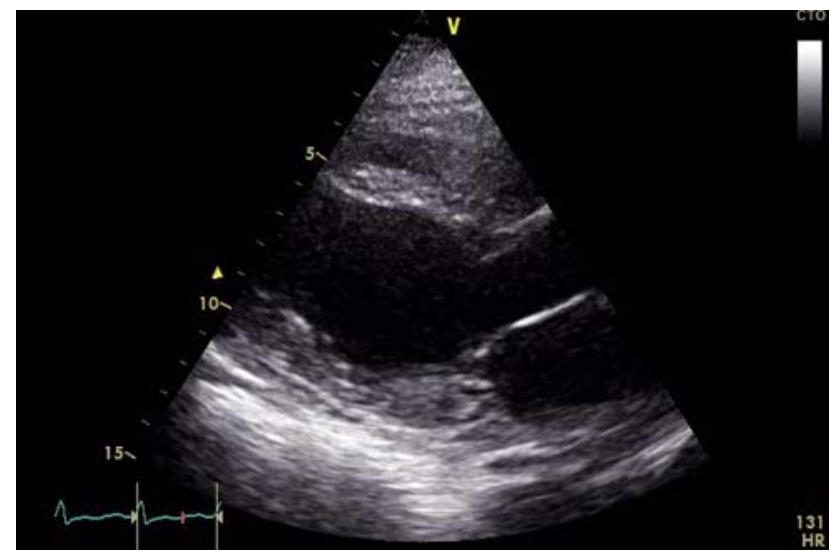

Figure 2

Takotsubo cardiomyopathy on echocardiogram - parasternal long axis on original presentation.

The diagnosis of stress induced cardiomyopathy was originally described in Japan (6). It is also called Takotsubo, meaning octopus trap which has a shape similar to the apical ballooning of the left ventricle. It has been linked with acute illness, emotional or physical stress (3). A number of hypotheses have been postulated for pathogenesis of the syndrome, including catecholamine excess. Hyperthyroidism in the context of radiation thyroiditis also mimics a state of adrenergic excess. Thyroid hormone is believed to act upon cardiac myocytes partially via upregulation of $\beta$-adrenergic receptors. However, the exact pathogenesis of the condition remains unclear (5) (7). Heart failure develops on the grounds of normal coronary angiography and medical treatment with diuretics, $\beta$ blockers as well as angiotensin-converting-enzyme (ACE) inhibitors result in full resolution of symptoms (3).

The first case of takotsubo cardiomyopathy complicating radiation thyroiditis was reported in a 73-year-old man from the Netherlands with a toxic multinodular goitre (1). He was initially treated with radioiodine therapy. Five years later, hyperthyroidism recurred and a second dose of radioactive iodine was administered. Four days later, he presented with irritation and signs of heart failure. He was hyperthyroid. Electrocardiography and ventricular angiography confirmed apical ballooning consistent with takotsubo cardiomyopathy. He was managed supportively and improved markedly after $24 \mathrm{~h}$. His cardiac function returned to normal after 7 weeks. Antithyroid medications were never used during the course of his thyroid disease. Although this patient was treated in a different country, clinical guidelines from the Royal College of Physicians recommend that patients with severe hyperthyroidism or elderly patients with signs of heart failure should be treated with an antithyroid drug to restore normal circulating thyroid hormone levels before radioiodine treatment (8). This way thyroid hormone stores get depleted and the risk of symptom exacerbation or thyroid storm after early radioactive iodine therapy is diminished.

Our patient received a full 12-month treatment with carbimazole, but still developed stress-induced cardiomyopathy secondary to post-ablative thyrotoxicosis. Postmenopausal women seem to be more at risk (3). A single centre retrospective study conducted to find the association of thyroid profile with takotsubo cardiomyopathy has shown that $11.36 \%$ of patients presenting with the syndrome over a 6 year period were found to be hyperthyroid. A significantly higher number (34.61\%) had a history of hypothyroidism. Precipitating stress was identified in only $24 \%$ patients (7). Risk factors for developing the syndrome require further evaluation.

Inpatient mortality from stress cardiomyopathy alone ranges from 0 to $8 \%$ and patients who survive the acute episode recover to normal cardiac function within one to 4 weeks (3). The Royal College of Physicians recommends that in the first 2 weeks following administration of radioiodine therapy, patients should be warned that exacerbation of thyrotoxic symptoms may be experienced. Prospective observational populationbased studies have not shown excess mortality during follow up after radioiodine treatment which has resulted in hypothyroidism, and this is strongly supportive of its safety (9).

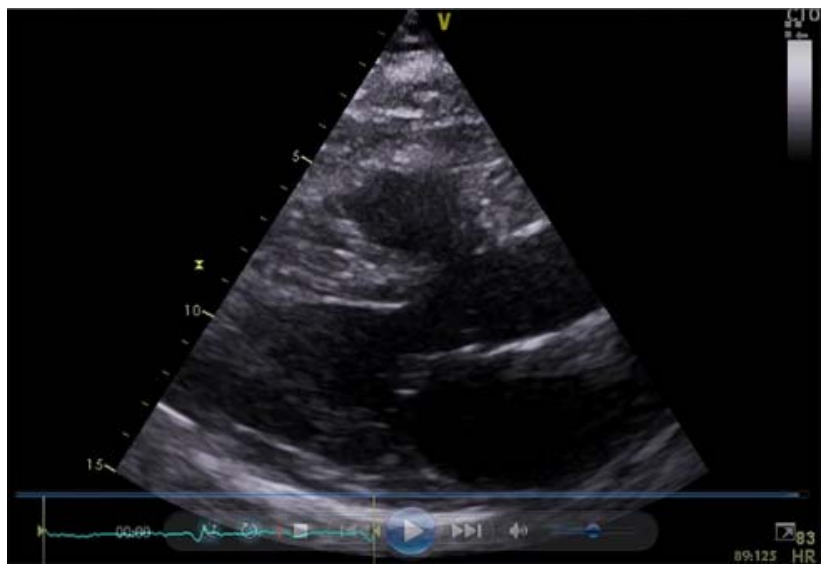

Figure 3

Takotsubo cardiomyopathy resolved echocardiogram - parasternal long axis, 6 weeks after original presentation. 


\section{Funding}

This research did not receive any specific grant from any funding agency in the public, commercial or not-for-profit sector.

\section{Declaration of interest}

The authors declare that there is no conflict of interest that could be perceived as prejudicing the impartiality of the research reported.

\section{Patient consent}

Written informed consent was obtained from the patient for publication of this case report.

\section{Author contribution statement}

Co-authors have contributed towards patient care, management and also towards writing and finalising the draft.

\section{References}

1 Van de Donk NW, America YG, Zelissen PM \& Hamer BJ 2009 Takotsubo cardiomyopathy following radioiodine therapy for toxic multinodular goitre. Netherlands Journal of Medicine 67 350-352.
2 Ross DS 2011 Radioiodine therapy for hyperthyroidism. New England Journal of Medicine 364 542-550. (doi:10.1056/ NEJMct1007101)

3 Bybee KA, Kara T, Prasad A, Lerman A, Barsness GW, Wright RS \& Rihal CS 2004 Systematic review: transient left ventricular apical ballooning: a syndrome that mimics ST-segment elevation myocardial infarction. Annals of Internal Medicine 141 858. (doi:10.7326/0003-4819141-11-200412070-00010)

4 Radhakrishnan A \& Granato JE 2009 An association between Takotsubo cardiomyopathy and thyroid storm. Postgraduate Medicine 121 126-130. (doi:10.3810/pgm.2009.05.2012)

5 Klein I \& Ojamaa K 2001 Thyroid hormone and the cardiovascular system. New England Journal of Medicine 344 501-509. (doi:10.1056/ NEJM200105103441901)

6 Sato H, Taiteishi H \& Uchida T. Takotsubo-type cardiomyopathy due to multivessel spasm. In Clinical Aspect of Myocardial Injury: From Ischemia to Heart Failure, p 56. Tokyo: Kagakuhyouronsha, 1990.

7 Aggarwal S, Papani R \& Gupta V 2015 Can thyroid break your heart? Role of thyroid in Takotsubo cardiomyopathy: a single center retrospective study International Journal of Cardiology 184 545-546. (doi:10.1016/ j.ijcard.2015.02.058)

8 Royal College of Physicians. Radioiodine in the management of benign thyroid disease: clinical guidelines. Report of a Working Party. London: RCP, 2007.

9 Boelaert K, Maisonneuve P, Torlinska B \& Franklyn JA 2013 Comparison of mortality in hyperthyroidism during periods of treatment with thionamides and after radioiodine. Journal of Clinical Endocrinology and Metabolism 98 1869-1882. (doi:10.1210/jc.2012-3459)

Received in final form 24 July 2015

Accepted 31 July 2015 